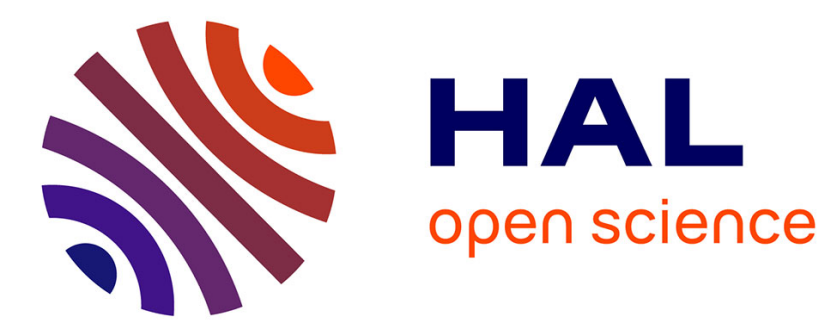

\title{
CFOSAT : A new mission in orbit to observe simultaneously wind and waves at the ocean surface
}

Danièle Hauser, Cedric Tourain, Jean-Michel Lachiver

\section{To cite this version:}

Danièle Hauser, Cedric Tourain, Jean-Michel Lachiver. CFOSAT : A new mission in orbit to observe simultaneously wind and waves at the ocean surface. Space Research Today, 2019, 206, pp.15-21. 10.1016/j.srt.2019.11.012 . hal-02371546

\section{HAL Id: hal-02371546 \\ https://hal.science/hal-02371546}

Submitted on 24 Nov 2020

HAL is a multi-disciplinary open access archive for the deposit and dissemination of scientific research documents, whether they are published or not. The documents may come from teaching and research institutions in France or abroad, or from public or private research centers.
L'archive ouverte pluridisciplinaire HAL, est destinée au dépôt et à la diffusion de documents scientifiques de niveau recherche, publiés ou non, émanant des établissements d'enseignement et de recherche français ou étrangers, des laboratoires publics ou privés. 
CFOSAT : A new mission in orbit to observe simultaneously wind and waves at the ocean surface

\author{
Danièle HAUSER(1), Cédric TOURAIN (2), Jean-Michel LACHIVER (2) \\ (1): LATMOS-IPSL, CNRS, Université Versailles Saint-Quentin, Sorbonne Université, \\ (2): Centre National d'Etudes Spatiales
}

\title{
1- INTRODUCTION
}

Since October 2018, a new space-borne system for measuring ocean surface parameters has been deployed, namely the CFOSAT (China France Oceanography Satellite) developed under the responsibilities of the French and Chinese Space agencies (CNES, CNSA) with a participation of the National Satellite Oceanic Application Service NSOAS. CFOSAT was designed to monitor at the global scale, ocean surface winds and waves with a twofold objective:

- $\quad$ improving our scientific knowledge of the air/sea interaction processes and sea-state climate, with a particular interest on wind/wave interactions, impact of waves on air-sea exchanges, interactions of wind and waves with currents and sea-ice, surface wind and wave evolution under climate change

- demonstrating the interest of a new concept for future operational missions which contribute to wind and wave field analysis, feeding forecast systems through assimilation.

The detailed objectives and characteristics have been presented in [1] and [2]. We recall here that CFOSAT is a very innovative mission for several reasons. First, thanks to its near-nadir Ku-Band scatterometer SWIM (Surface Investigation and Monitoring), it is the first time that directional spectra of ocean waves are produced systematically with a real-aperture radar system. This usefully complements the existing missions based on SAR (Synthetic Aperture Radar) systems which also provide spectral information on surface ocean waves but with more limitations [3]. Secondly, the mission provides simultaneous and collocated measurements of wind and waves, which is very important to better validate wave models, progress in the wave physics and air-sea interaction process analysis. Furthermore, the two Ku-Band radar instruments on-board CFOSAT (SWIM and a wind scatterometer called CSCAT) are both new technical concepts, with for both, a fan beam rotating scanning geometry, which have pushed the technology ahead.

Since the launch date, the main activities have been devoted to the calibration of the instruments and to the validation of the scientific products. This paper gives a summary of the first results of this CAL/VAL activity regarding the SWIM instrument. In section 2, we first recall the main characteristics of the mission and instruments and then present the main results in section 3 to 5 . A conclusion is given in section 6 .

\section{2- MAIN CHARACTERISTICS OF THE MISSION AND OF THE SWIM INSTRUMENT}

To meet the objectives recalled in the introduction, the satellite carries two payloads; both are Ku-band (13.2 to $13.6 \mathrm{GHz}$ ) radars scanning around the vertical axis:

- the wave scatterometer SWIM, a rotating 6-beam radar at small incidence angles $\left(0\right.$ to $\left.10^{\circ}\right)$ [2],

- the wind scatterometer SCAT, a fan-beam radar at larger incidence angles (26 to $46^{\circ}$ ) [4].

The orbit was chosen as polar ( $97.465^{\circ}$ inclination), at an altitude of $519 \mathrm{~km}$ and sun-synchronous with a 13-day repeat cycle.

As for the SWIM instrument, the concept is based on a scanning-beam real-aperture radar, following the ideas proposed in the 1980's by Jackson et al. [5], both for airborne and space-borne configurations, in order to avoid the limitations of SAR imaging in terms of the retrieval of directional spectra of ocean waves. This concept has been implemented and validated on various airborne systems, but SWIM is the first space-borne instrument working with this concept. SWIM is based on a multi-incidence and scanning azimuthal geometry (Figure 1). It illuminates the surface sequentially with 6 incidence angles: $0^{\circ}, 2^{\circ}, 4^{\circ}, 6^{\circ}, 8^{\circ}$ and $10^{\circ}$, each beam with a beam aperture in elevation and in azimuth of $1.5^{\circ}$ to $1.8^{\circ}$ (see [2]). Accounting for the orbit altitude, the footprint dimension of each beam is about $18 \mathrm{~km} \times 18 \mathrm{~km}$, and the full swath for the outer beam (10 $\left.{ }^{\circ}\right)$ is about $90 \mathrm{~km}$ in radius. In order to characterize the wave properties in all azimuth directions, the antenna beam is rotated at a speed rate of $5.6 \mathrm{rpm}$, which generates, when combined with the satellite advection, some overlap in the 
sampling of successive rotations (see [2]). The $0^{\circ}$ beam is used to estimate wind and wave parameters as in altimeter missions. The $6^{\circ}, 8^{\circ}$, and $10^{\circ}$ are used to estimate the directional spectra of ocean waves. This requires a high range resolution which was chosen as $0.47 \mathrm{~m}$. All the beam incidences are used to characterize the surface roughness from the mean trend of the normalized radar cross-section from 0 to $10^{\circ}$ incidence.

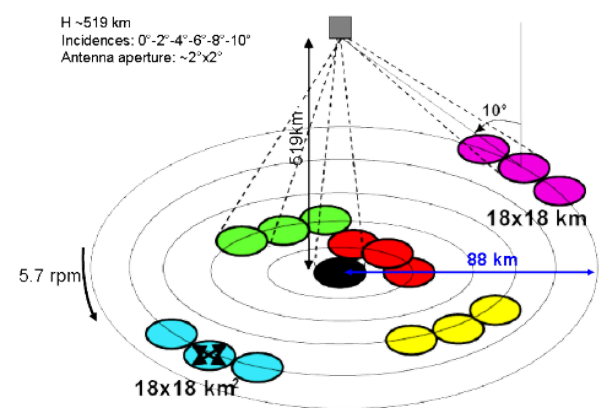

Figure 1 : geometry of SWIM beams (0 to $10^{\circ}$ incidence)

The main products delivered from the SWIM instrument are:

- Significant wave height (SWH) and wind speed from nadir measurements:

- Directional wave spectra and their parameters from off-nadir beams pointing at $6^{\circ}, 8^{\circ}, 10^{\circ}$ mean incidences. These are provided as in wave cells on each side of the nadir track, and which size is about $70 \mathrm{~km}$ along-track and $90 \mathrm{~km}$ across-track

- Normalized radar cross-section profiles from $0^{\circ}$ to $10^{\circ}$ either in the radar geometry or in the wave cell geometry.

Details on the theoretical basis of the concept, on wave spectra inversion from SWIM observations and on the products can be found in [2]. The main idea is to measure with a horizontal resolution of a few meters, the fluctuations of the normalized radar cross-section within the footprint in the look direction, and to relate them to the slope of the long waves which locally tilt the surface. In each look direction the spectrum of fluctuation is related to the slope spectrum of surface waves. Using a rotating system, this enables to estimate the directional spectrum of wave slopes (or heights).

The in-flight validation of the SWIM instrument shows very good performances, in line with the specification regarding the Point Target response, pointing accuracy, and even above the specification for the Signal to noise Ratio. These good performances combined with the signal tracking algorithm implemented in the on-board processing allows to acquire signals over all surfaces (ocean, sea ice, continents) except on the very high topography (Himalaya,..)

\section{3- WIND AND SIGNIFICANT WAVE HEIGHT FROM THE NADIR BEAM}

In a way similar to standard satellite altimeter missions, geophysical parameters from the nadir echo waveform over the ocean are estimated by applying a "retracking" algorithm [6] to the recorded waveforms. For SWIM however, no information is provided on the epoch or height because CFOSAT is not an altimeter mission (no precise orbit determination, no microwave radiometry nor dual wavelength measurement for delay correction). Over ocean surfaces, the main geophysical products are hence the significant wave height, the normalized radarcross-section, and the wind speed. An innovative algorithm, namely the "Adaptive retracking" has been implemented.

The assessment of these parameters has been carried out by comparing to parameters from numerical models (in particular the ECMWF atmospheric and the wave forecasting WAM model from Meteo-France called MFWAM) and by analyzing comparisons over cross-over points with the Jason3 and SARAL/AltiKa missions.

Without doing any particular post-processing correction and despite the low measurement rates (nadir echoes provided at $5 \mathrm{~Hz}$ ), the results indicate an excellent accuracy for Hs estimation with almost no bias (typically $1 \mathrm{~cm}$ to $6 \mathrm{~cm}$ depending on the data set used for comparison) and very small rms errors (28 to $35 \mathrm{~cm}$ depending on the data set used for comparison). Similarly, the wind speed is retrieved with a very good accuracy $(0.10 \mathrm{~m} / \mathrm{s}$ 
mean bias and rms error of the order of $1 \mathrm{~m} / \mathrm{s}$ with respect to ECMWF winds. First results analyzed by the international science team also show very good agreement with buoy data.

\section{4- THE NORMALIZED RADAR CROSS-SECTION AT NEAR-NADIR INCIDENCE ANGLES}

The normalized radar cross-section (NRCS) at near nadir incidence characterizes the surface roughness which impacts the quasi-specular reflection of the electromagnetic wave by the surface. With the SWIM instrument NRCS is provided from the echo power (after full calibration) in a diversity of incidence angles (from 0 to $11^{\circ}$ ) and azimuth angles $\left(0-360^{\circ}\right)$. Over the ocean, it is at the same time a parameter which contains information on the statistics of surface slopes [7] and a parameter that is used in the transformation of the signal fluctuations measured from the off-nadir beams to wave spectra ([2]). Its assessment has been carried out by comparing to the mean level and general trends provided by the Global Precipitation Mission (GPM) Precipitation Radar data sets (similar geometrical configuration, same radar Band). It was verified that its behavior with incidence, and for each incidence with wind speed is very consistent with the GPM data. Measurements over sea-ice and over continental surfaces also provide very consistent values.

\section{5- WAVE SPECTRA FROM THE OFF-NADIR BEAM}

As for the wave spectra, an example of the current product is shown in Fig 2a. It is a polar representation with a $180^{\circ}$ ambiguity in direction. It shows two main wave components one which is almost aligned along the WestEast direction and has a maximum of energy at low wavenumbers (wavelength of about 250 to $300 \mathrm{~m}$ ) and one which is spread between northwest-northeast (or southeast-northwest) with maximum of energy at higher wavenumbers (wavelength of about $70 \mathrm{~m}$ ). Compared to the collocated spectrum from the MFWAM model (Fig.2c), it is evident that this spectrum exhibits a parasite effect in two azimuth sectors (with $180^{\circ}$ symmetry). We could check that this is a systematic effect, due to an increase of speckle noise in the along-track direction. This noise is currently not completely well corrected and this explains this perturbation. In the other azimuth sectors, the directional properties of the waves are qualitative agreement with the MFWAM model. Tests are under progress to better account for noise corrections. Figure $2 b$ shows that with an updated correction for speckle noise rejection, this largely improves the comparison with the MFWAM model. As this speckle noise model is not yet fully established the spectra are currently provided by masking a sector of $\pm 15^{\circ}$ in the alongtrack direction.

Figure 3 shows maps of significant wave height, dominant direction and dominant wavelengths estimated from the first partition extracted from the SWIM spectra (current products with a mask). They are compared to similar parameters provided by the MFWAM model. The first partition characterizes in each case, the wave system with the largest energy. Overall these maps show that SWIM is able to provide very promising wave parameters. Although the significant wave height is currently overestimated for wave heights smaller than about $4 \mathrm{~m}$ (because of an insufficient subtraction of speckle noise), the direction and wavelength are overall in agreement with the model except in some regions of the globe, where SWIM spectra are perturbed by the speckle noise problem. Work is under progress to mitigate this effect. Furthermore, the present results were obtained by using a simple association between SWIM partitions and MFWAM partitions without cross-assignments. This may introduce some differences in the SWIM/model comparison. 
(a)

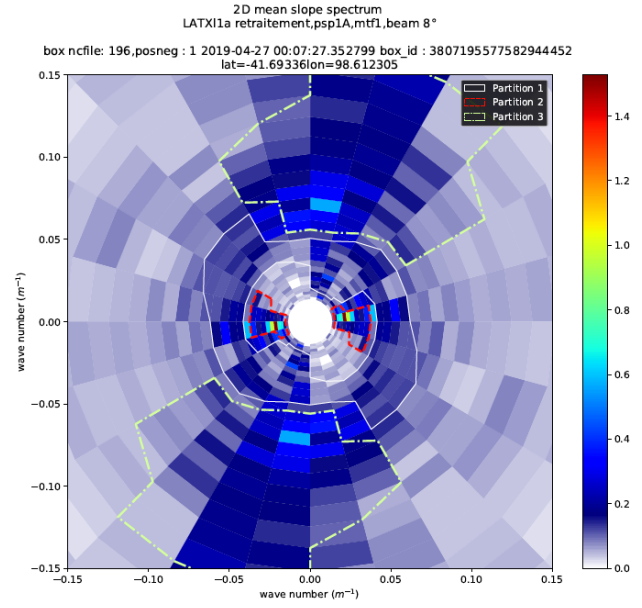

(b)

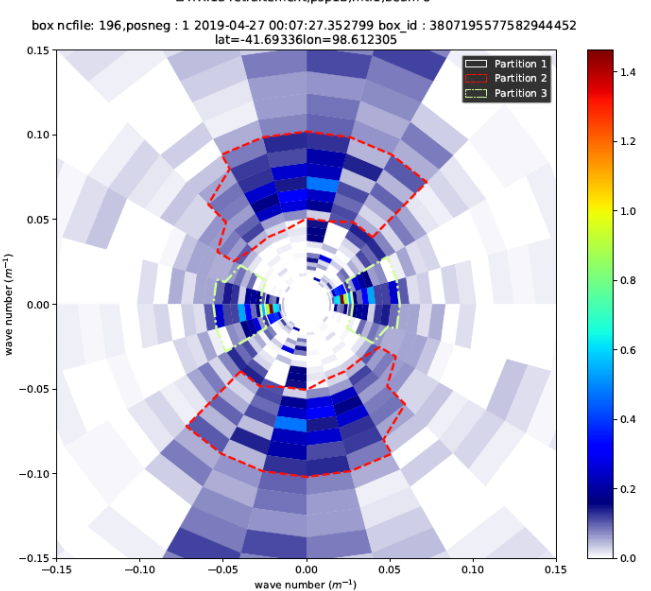

(c)

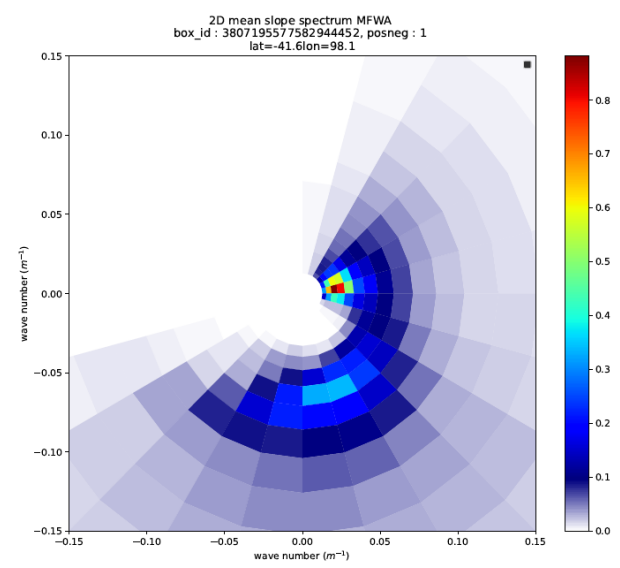

Figure 2: Directional spectrum of wave slopes from (a) SWIM current processing (b) SWIM alternative processing which uses a new model for the speckle noise correction (c) the MFWAM numerical model 


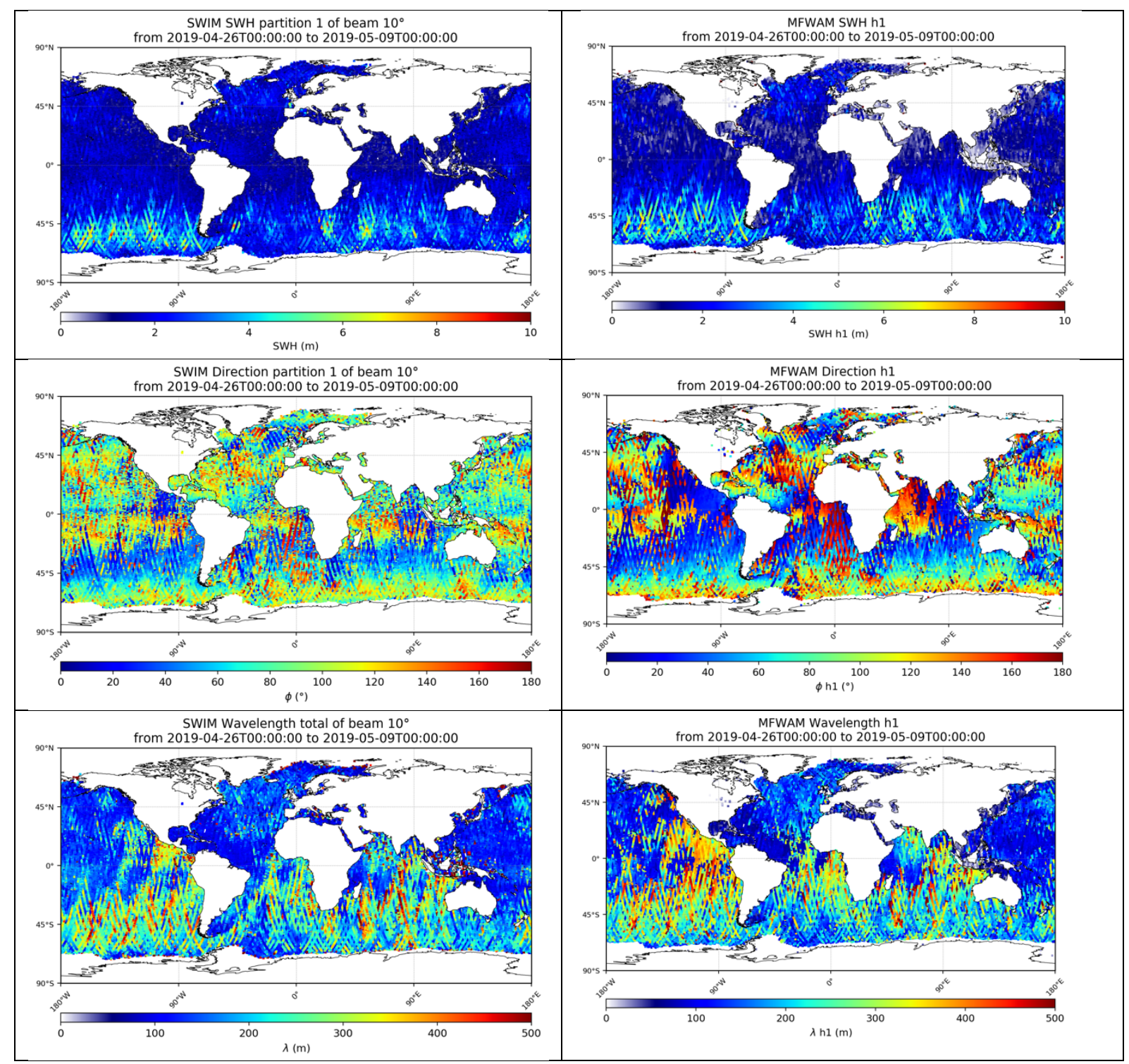

Figure 3: Maps of SWIM (left column) et MFWAM (right column) wave parameters of the first spectral partition for a period of about 13 days starting on April $26^{\text {th }} 201902$ :00. From top to bottom: Significant wave height, dominant direction, dominant wavelength of the first partition. The SWIM results are shown for the $10^{\circ}$ incidence beam. The partitions have been estimated separately on the SWIM and on the MFWAM spectra and associated a posteriori by choosing in each case the most energetic partition.

\section{6- CONCLUSION}

The first results obtained from the SWIM instrument during the CAL/VAL phase of the CFOSAT satellite have been presented. The CAL/VAL phase has shown that the instrument works perfectly well, and that the wind and wave parameters retrieved from the nadir pointing beam are obtained with an excellent accuracy. As for the spectral wave parameters, the analysis of these new products shows very promising results. Waves are detected in the range $[70-500 \mathrm{~m}]$ of wavelength with consistent wavelengths and directions although the results are currently perturbed by noise effects. Work is in progress to mitigate this noise effect. The observations from SWIM have also been assessed by analyzing omni-directional spectra form SWIM and buoy observations as well as evolution of waves in different individual situations (not illustrated here), as wave growth in fetch limited conditions, wave modifications in surface current regions or waves in the surrounding of hurricanes. Hence it confirms that SWIM brings new information on the spectral properties of waves over the globe. Since autumn 2019, data sets are made available to the scientific community, to be used for scientific studies on waves and their impact on the ocean/atmosphere coupled system, and to prepare assimilation of observations in the numerical wave model systems of operational centers. Observations may also be used to improve analyses of other remote sensing data (altimeter data, impact on waves on the so-called sea-state bias in the ocean topography estimation, combination with passive microwave observations like those dedicate to sea surface salinity, SAR observations, 
etc). Finally note that in addition to the new information brought to oceanography by CFOSAT, this mission will also be able to complement other existing missions for the estimation of land surface parameters (soil moisture and soil roughness), and polar ice sheet characteristics through the normalized radar cross-section measured in Ku-Band in a diversity of near-nadir incidence angles and azimuth directions.

On October $29^{\text {th }} 2019$ we celebrate the first anniversary of the satellite in orbit. During the first year after launch, the calibration of instruments, the validation of the scientific products have been successfully completed, and the inversion algorithmic chains improved. Starting during fall 2019

the scientific products will be made accessible to scientific users by both the French and Chinese missions centers. In France, this will be accessible through the AVISO+ website

(https://www.aviso.altimetry.fr/en/missions/current-missions/cfosat.html). This concretizes the continuation of thirteen years of sino-french cooperation in oceanic space research.

\section{REFERENCES}

[1] Hauser D., et al., "Overview of the CFOSAT mission”, IGARSS'2016, Beijing (China), July 2016

[2] Hauser D., C. Tison, T. Amiot, L. Delaye, N. Corcoral et al, SWIM: the first spaceborne wave scatterometer, IEEE Trans. on Geoscience and remote Sensing, 10.1109/TGRS.2017.2658672, VOL 55, 5, May 2017

[3] W. R. Alpers and C. Brüning, "On the relative importance of motion related contributions to the SAR imaging mechanism of ocean surface waves,” IEEE Trans. Geosci. Remote Sens., vol. GE-24, no. 6, pp. 873-885, Nov. 1986

[4] Dong Xiaolong, Zhu Di, W. Lin, H. Liu, J. Jiang, "A Ku-band rotating fan-beam scatterometer: design and performance simulations", IGARSS'10, 2010

[5] Jackson F. C., W. T. Walton, and P. L. Baker, Aircraft and satellite measurement of ocean wave directional spectra using scanning-beam microwave radars, J. Geophys. Res., Vol. 90, 987-1004, 1985

[6] Brown, G . S., The average impulse response of a rough surface and its applications, IEEE Trans. Antenna Propagat.2, 5(1), 67-74, 1977.

[7] Barrick, D.E., 1968. Relationship between slope probability density function and the physical optics integral in rough surface scattering. Proc. IEEE 56 (10), 1728-1729. 